\title{
Acquired Idiopathic Pure Red Cell Aplasia in a Hemodialyzed Patient with Inactive Systemic Lupus Erythematosus
}

\author{
Hirokazu Okada, Hiromichi Suzuki, Hideo Uchida, Yoshihiko Kanno, Yuko Kitamura, \\ Tadakazu Hisamatsu, Nobuhiro Deguchi*, Daisuke Hayashi** and Takao Saruta
}

A male patient suffered chronic renal failure due to lupus nephritis and was undergoing hemodialysis. Six years after beginning hemodialysis, anemia developed, which improved by erythropoietin. Unresponsiveness to erythropoietin gradually appeared, and with a suspicion of pure red cell aplasia, he was treated with a high-dose corticosteroid but the unresponsiveness did not improve. Neither his serum nor lymphocytes inhibited erythropoiesis of either normal bone marrow stem cells or his own in vitro. These observations suggest an impaired hematopoietic microenvironment in his bone marrow.

(Internal Medicine 33: 492-495, 1994)

Key words: erythropoietin, corticosteroid, bone marrow stem cell

\section{Introduction}

We report a middle-aged male patient undergoing regular hemodialysis for 7 years due to lupus nephritis, and presenting with refractory anemia similar to pure red cell aplasia (PRCA). Clinical pictures and in vitro analysis of the bone marrow mononuclear cells indicated autoimmunity $(1-4)$ or other known factors, i.e., thymoma, drugs, viral infections, or malignancy (1, 5,6 ), and these factors did not seem to play a role in the pathogenesis of the present case of PRCA. Recently, human recombinant erythropoietin (EPO) has become available for patients who need regular dialysis, and almost all the anemia associated with chronic renal failure has been believed to be treatable with EPO (7-11). In spite of in vitro effectiveness of EPO, however, administration of high-dose EPO for 6 months was ineffective in the present case. To our knowledge, this is the first report of a hemodialyzed patient with inactive systemic lupus erythematosus who presented with idiopathic PRCA resistant to high-dose EPO and corticosteroid.

\section{Case Report}

A 43-year-old male hemodialyzed patient presented complaining of refractory anemia resistant to regular administration of EPO (9,000 U/week). He had been diagnosed with systemic lupus erythematosus (SLE) with polyarthritis, proteinuria, an- tinuclear antibodies and LE cell 11 years before. He had been undergoing regular hemodialysis due to lupus nephritis for the 7 years since 1984. At the introduction of hemodialysis, his hemoglobin level was $7.5 \mathrm{~g} / \mathrm{dl}$.

Administration of 3,000 U/week EPO during regular hemodialysis was successfully introduced in this patient in February 1990 because of the diagnosis of normocytic and normochromic anemia. Since the level of hemoglobin began to decrease in January 1991 despite increases in the dose of EPO, blood transfusion was intermittently carried out. Discontinuing prescribed drugs, i.e., enalapril, ticlopidine, $\mathrm{Al}(\mathrm{OH})_{3}$, administration of iron, multiple vitamins, anabolic steroid, and increased doses of a corticosteroid were all ineffective. The number of peripheral reticulocytes had been below $1 \%$ of the peripheral total blood cell count, and the bone marrow aspiration and biopsy specimens revealed hypoplasia of immature erythroid cells with normal myeloid and megakaryocytic quantities (myeloblasts $2.0 \%$, promyelocytes $0.8 \%$, myelocytes- $\mathrm{N}$ $8.0 \%$, metamyelocytes $12.6 \%$, bands- $\mathrm{N} 21.0 \%$, segs-N $31.0 \%$, segs-E $4.2 \%$, segs-B $0.4 \%$, lymphocytes $14.0 \%$, monocytes $4.6 \%$, plasma cells $1.2 \%$, reticulum cells $0.2 \%$, pronormoblasts $0.2 \%$, normoblasts-poly $0.2 \%$, mitotic cells $0.2 \%$, M/E ratio 200.0), indicating a possible diagnosis of PRCA (Fig. 1). No green coloration was detected in the bone marrow biopsy under polarized light microscopy after staining with Congo red. For further evaluation and treatment, he was admitted to our hospi-

From the Department of Internal Medicine, *Central Dialysis Unit, Keio University School of Medicine, Tokyo and **Division of Dialysis, Shimada General Hospital, Choushi

Received for publication November 11, 1993; Accepted for publication May 26, 1994

Reprint requests should be addressed to Dr. Takao Saruta, the Department of Internal Medicine, Keio University School of Medicine, Shinanomachi 35, Shinjuku-ku, Tokyo 160 


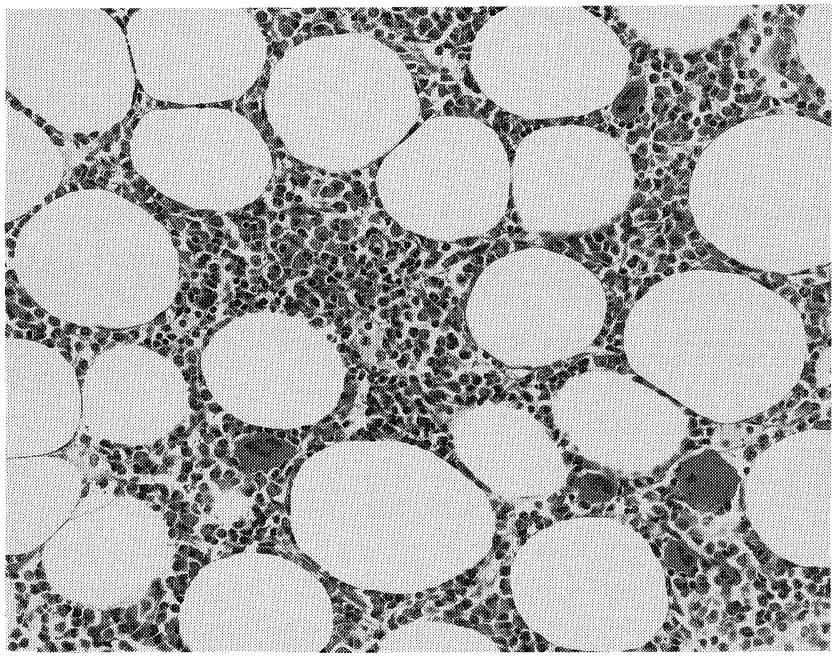

Fig. 1. Patients bone marrow biopsy specimen. General appearance is hypocellular. Immature erythroid cells are apparently hypoplastic, but the numbers and morphology of myeloid series as well as megakaryocytes are normal. Hematoxylin-eosin stain (HE stain, $\times 240$ ).

tal on August 2, 1991. On physical examination, he was a moderately developed, pale man. Conjunctivae were severely anemic, but not icteric. Neither thyromegaly nor cervical lymphadenopathy were present. Auscultation did not find any abnormalities in the lungs and the heart. Hepatosplenomegaly was absent, and no other abdominal masses were felt. An arteriovenous fistula was on his left arm. Neurological examinations revealed no abnormalities. Occult fecal blood was negative. The white cell count was 8,800 per microliter, red cell count was 2.48 million per microliter, hemoglobin level was 6.8 $\mathrm{g} / \mathrm{dl}$, the reticulocyte level was $1 \%$, hematocrit was $21.2 \%$. Mean cell volume (MCV), mean cell hemoglobin $(\mathrm{MCH})$, and mean cell hemoglobin concentration (MCHC) were $86 \mathrm{fl}, 27.4$ $\mathrm{pg}$, and $32.1 \mathrm{~g} / \mathrm{dl}$ respectively, and platelets were 530 thousands per microliter. Erythrocyte sedimentation rate was $82 \mathrm{~mm} / \mathrm{hr}$. The biochemical data were serum total protein $6.7 \mathrm{~g} / \mathrm{dl}$, serum albumin $2.6 \mathrm{~g} / \mathrm{dl}$, blood urea nitrogen $96.2 \mathrm{mg} / \mathrm{dl}$, serum creatinine $14.5 \mathrm{mg} / \mathrm{dl}$, glutamic oxaloacetic transaminase 12 IU/l, glutamic pyruvic transaminase $12 \mathrm{IU} / \mathrm{l}$, lactic dehydrogenase $226 \mathrm{IU} / \mathrm{l}$, alkaline phosphatase $165 \mathrm{IU} / \mathrm{l}$, creatine phosphokinase $49 \mathrm{IU} / \mathrm{l}$, amylase $478 \mathrm{IU} / \mathrm{l}$, glucose $119 \mathrm{mg} / \mathrm{dl}$, C-Reacting protein $0.18 \mathrm{mg} / \mathrm{dl}$, sodium $137.1 \mathrm{mEq} / \mathrm{l}$, potassium $5.3 \mathrm{mEq} / \mathrm{l}$, chloride $104 \mathrm{mEq} / \mathrm{l}$. Iron stores were plentiful (serum iron, total iron binding capacity, and ferritin were 244 $\mu \mathrm{g} / \mathrm{dl}, 254 \mathrm{mg} / \mathrm{dl}$, and 1,700 $\mathrm{ng} / \mathrm{dl}$ respectively). These biochemical data indicated the presence of chronic renal failure compensated skillfully by hemodialysis. Intravascular hemolysis was negligible because of the normal level of haptoglobin (564 $\mathrm{mg} / \mathrm{dl})$. The serum concentrations of inorganic phosphate (4.7 $\mathrm{mg} / \mathrm{dl})$, aluminium $(3.5 \mu \mathrm{g} / \mathrm{dl})$ and parathyroid hormones (PTH-C 16.7 ng/ml, PTH intact 198 pg/ml, PTH-M 49,700 ng/ $\mathrm{ml}$ ) were above the normal range, but within the levels usually detected in hemodialyzed patients. A large dose of EPO was administered just before each hemo-dialysis so the EPO serum level was high enough $(936 \mathrm{mU} / \mathrm{ml})$. Although diffuse and speckled type antinuclear antibodies were positive, the titer of anti-dsDNA antibodies was only $4.1 \mathrm{IU} / \mathrm{ml}$.

Antiphospholipid antibody was $3.0 \mathrm{U} / \mathrm{ml}$. LE test, RA test, anti Sm antibody, anti SS-A, and B antibody were all negative. Serum immunoglobulins G, A, and M were 1,259, 289, and 367 $\mathrm{mg} / \mathrm{dl}$ respectively, and serum complement 3 and 4 were 50 and $40 \mathrm{mg} / \mathrm{dl}$ respectively. In spite of the repeated tests, anti-EPO antibodies were undetectable. Chest-radiographs, electrocardiogram, esophago-gastro-duodenography, chest- and abdominal-computed tomography were unremarkable. These findings and the normal serum levels of tumor markers suggested that malignancy was unlikely. Neither direct inhibitory factors in the serum nor suppression by T-lymphocytes were revealed by in vitro analysis of the bone marrow mononuclear cells, and the existence of responsiveness to EPO in the stem cells was suspected (see below). However, administration of high-dose EPO (9,000-27,000 U/week) for 6 months was ineffective.

\section{Materials and Methods}

\section{Bone marrow mononuclear cells (MNC)}

The bone marrow samples were obtained by posterior iliac crest aspiration from the patient and a healthy donor for bone marrow transplantation. Bone marrow MNC were isolated after Ficoll-Hypaque (Pharmacia, Uppsala, Sweden) gradient centrifugation and suspended in alpha-MEM (GIBCO, Grand Island, NY, U.S.A.) supplemented with $1 \%$ penicillin and streptomycin. To separate T-lymphocytes from the MNC, sheep erythrocyte rosette formation method was used. Briefly, MNC were incubated with $10 \%(\mathrm{v} / \mathrm{v})$ of sheep erythrocyte suspension in fetal calf serum (FCS) (GIBCO) for 60 minutes at room temperature, and then T-lymphocyte-depleted MNC were isolated from the interphase after Ficoll-Hypaque gradient centrifugation.

\section{Burst forming units - erythroid (BFU-E) assay}

Total MNC or T-lymphocyte-depleted MNC were plated at $2 \times 10^{5}$ cells $/ \mathrm{ml}$ in $35 \mathrm{~mm}$ tissue culture dishes, each containing $1 \mathrm{ml}$ mixture of alpha-minimum essential medium, $1.2 \%$ methyl cellulose (SIGMA, St. Louis, MO, U.S.A.), 30\% FCS, $10 \%$ normal human serum, $1 \%$ deionized bovine serum albumin (SIGMA), $5 \times 10^{-5} \mathrm{M}$ 2-mercaptoethanol (SIGMA), 2 units of EPO, 10 ng of recombinant human granulocyte-colony stimulating factor (G-CSF), $10 \mathrm{ng}$ of recombinant human interleukin3 (IL-3). Each culture was done in four separate dishes. To investigate the influence of the patient's serum against MNC, $10 \%$ of the patient's stored serum was added instead of $10 \%$ normal human serum to the control mixture described above. Dishes were incubated at $37^{\circ} \mathrm{C}$ in a humidified atmosphere flushed with $5 \% \mathrm{CO}_{2}$ in air. The number of BFU-E colonies ( $>40$ cells/aggregate) were counted using an inverted microscope after 14 days of incubation. 


\section{Results}

The colony assay for BFU-E were performed under various conditions. Although the data did not have statistical significance by Student's t test, the results seemed to be interpreted as below. With EPO, G-CSF and IL-3, a moderate number of erythroid bursts from the patient's total MNC was formed (Fig. 2 ), although fewer than that from the control total MNC. The number of colonies arising from the patient's T-lymphocytedepleted MNC were fewer than that from the patient's total MNC. Otherwise, with the addition of the patient's serum, BFU-E formation of the patient's total MNC was apparently increased (Fig. 2), although the patient's serum did not affect BFU-E formation of the control total MNC.

\section{Discussion}

This report describes a rare case of a hemodialyzed patient with idiopathic PRCA. To our knowledge, the relationship between PRCA and chronic renal failure on regular dialysis has never been documented. Some patients with SLE presenting with PRCA were reported (12-17). Most patients with SLE show hematological disorders such as anemia, and the number of erythroid progenitor cells was often decreased in the bone marrow of anemic patients with SLE (18). Moreover, Otsuka et al. detected hematological abnormalities were also likely to occur at the multipotent stem cell level of such patients in vitro (19). As a cause of severe anemia, either circulating inhibitors of erythropoiesis including autoantibodies (20-22) or suppressor cellular autoimmunity (23-25) have been implicated, and clinical manifestations of such a hematological disorder usually appear with aggravation of SLE and is indicated by the increase in the titer of circulating anti-dsDNA antibodies.

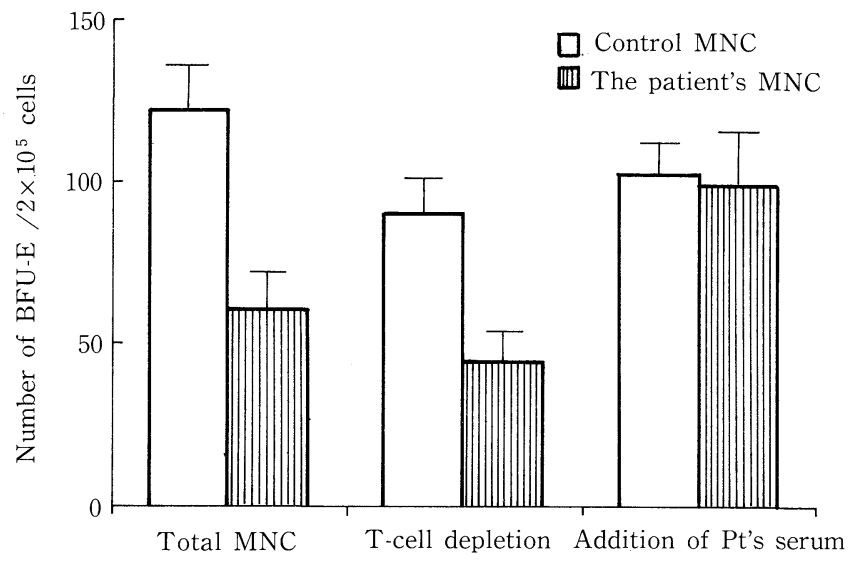

Fig. 2. BFU-E colony assay of bone marrow MNC of the patient and a healthy control, with or without T-lymphocyte depletion or addition of the patient's serum. BFU-E colonies were moderately formed from the patient's total MNC, although fewer than those from the control total MNC. T-lymphocyte depletion similarly reduced the colony number of each MNC. Addition of the patient's serum increased the formation of BFU-E not from the control total MNC, but from the patient's total MNC. Data of the number of colonies are mean $\pm \mathrm{SE}$ for assays in four separate dishes.
However, patients with end-stage renal failure undergoing regular dialysis due to lupus nephritis often show SLE decreased activity and are unlikely to manifest further disorders related to SLE $(26,27)$. Although there have been some exceptional cases with clinically active SLE receiving dialysis (26-29), they responded easily to administration of corticosteroids. Therefore, the PRCA that occurred in this patient treated with high-dose of corticosteroids did not seem to be dependent on autoimmunity associated with SLE. The activity of in vitro BFU-E formation of the patient's total MNC demonstrated that those cells could respond to hematopoietic factors supplemented in the culture medium in vitro. The difference in the erythropoietic activity of MNC of the present patient between in vitro and in vivo leads us to postulate that some suppressor factors and/or essential factors such as IL-3 existed, which were supplemented in the culture medium, and were insufficient in vivo. According to the observation of the in vitro study with T-lymphocyte depletion and the addition of the patient's serum, T-lymphocytes or circulating suppressor factors were unlikely to be associated with the present hematological disorder, which was incompatible with the usual findings of patients with PRCA and/or SLE (1-4, 12, 18-24). On the other hand, the activity of the patient's total MNC was lower than that of the control MNC (Fig. 2). This observation might be explained by abnormalities in the bone marrow stem cell itself, e.g., effects of uremic toxins (7), subclinical SLE-related disorders $(18,19)$ or persistent viral infection, especially by B19 parvovirus $(1,30)$, and the possibility that such abnormalities in the bone marrow stem cell itself played a role in the present case of PRCA cannot be ruled out. In addition, unknown hematopoietic factors other than EPO were also supposed to be in the patient's serum because the addition of the serum to the control medium which was fully supplemented with recombinant EPO induced marked BFU-E formation from the patient's total MNC. The control total MNC did not react with the patient's serum, leading to a speculation of enhanced reactivity to those factors in the patient's MNC that were masked in vivo. Marmont reviewed several treatments of PRCA (31), but some of them were ineffective and others involving immunosuppression were not applicable to this malnourished and immunocompromised patient. Meanwhile, Aoki and colleagues (32) reported in vitro responsiveness of bone marrow erythropoietic stem cells in aplastic anemia and myelodysplastic syndrome to EPO, and in vivo therapeutic potentials of EPO for these diseases were proposed. Although bone marrow cells of the present patient certainly responded to EPO in vitro, administration of highdose EPO for 6 months failed to improve the anemic state. Anemia in patients with chronic renal failure occurs due to a number of causes $(7,33,34)$, and Scigalla and colleagues (8) and Drueke $(9,10)$ reviewed several modulating factors involved in the hematopoietic response to EPO, but those factors could be eliminated and/or overcome by high-dose or long-term administration of EPO (11). Recently, it has been reported that systemic amyloidosis can reduce the hematopoietic response of hemodialyzed patients to EPO (35). Those modulating factors were negligible in the present patient, and we speculate that 
some suppressor factors may work and/or some essential factors may be insufficient in the hematopoietic microenvironment, interrupting hematopoiesis in the bone marrow of this patient. Certainly, abnormalities in the hematopoietic microenvironment of patients with SLE were pointed out by Otsuka and colleagues (36), and they proposed that a diminished production of hematopoietic growth factors by bone marrow fibroblastoid cells as a result of a diminished activity of monocyte derived factors may be one cause of the hematocytopenia which occurs in patients with SLE. Their consideration was compatible with the present findings of the in vitro analysis, and it cannot be denied that similar pathogenetic mechanisms played a role in the present patient in spite of clinically inactive SLE.

Acknowledgments: The authors are deeply grateful to Kirin Brewery Co., Ltd., and Sankyo Pharmaceutical Co., Ltd., for providing EPO, G-CSF and IL3 , and technical support.

\section{References}

1) Ammus SS, Yunis AA. Acquired pure red cell aplasia. Am J Hematol 24: 311, 1987.

2) Dessypris EN. The biology of pure red cell aplasia. Semin Hematol 28: 275, 1991.

3) Hanada $\mathrm{T}$, Abe T. Inhibitory factors to hematopoiesis in aplastic anemia and pure red cell aplasia. Acta Hematol Jpn 51: 1572, 1988.

4) Nagasawa M, Okawa H, Yata J. A B cell line from a patient with pure red cell aplasia produces an immunoglobulin that suppresses erythropoiesis. Clin Immunol Immunopathol 61: 18, 1991.

5) Agudelo CA, Wise CM, Lyles MF. Pure red cell aplasia in procainamide induced systemic lupus erythematosus. Report and review of the literature. J Rheumatol 15: 1431, 1988.

6) Abkowitz J. Retrovirus-induced feline pure red blood cell aplasia: Pathogenesis and response to suramin. Blood 77: 1442, 1991.

7) Eschbach JW. The anemia of chronic renal failure: Pathophysiology and the effects of recombinant erythropoietin. Kidney Int 35: 134, 1989.

8) Scigalla P, Messinger D, Wieczorek L. Reasons for differences in dose requirements of recombinant human erythropoietin in haemodialysis patients. Contr Nephrol 82: 55, 1990.

9) Drueke TB. Resistance to recombinant human erythropoietin in hemodialysis patients. Am J Nephrol 10: S34, 1990.

10) Drueke TB. Modulating factors in the hematopoietic response to erythropoietin. Am J Kidney Dis 18: S87, 1991.

11) Fukushima $Y$, Nakamoto $Y$, Miura $A B$, Miyagata $S$, Tsuchida $S$. The inhibitory factors of hematopoiesis in chronic hemodialysis patients treated with recombinant human erythropoietin. Tohoku J Exp Med 161: 217, 1990.

12) Daughaday WH. Lupus erythematosus with severe anemia, selective erythroid hypoplasia and multiple red blood cell iso-antibodies. Am J Med 44: 590, 1968.

13) Caassileth PA, Myers AR. Erythroid aplasia in systemic lupus erythematosus. Am J Med 55: 706, 1973.

14) Meyer RJ, Hoffman R, Zanjani ED. Autoimmune hemolytic anemia and periodic pure red cell aplasia in systemic lupus erythematosus. Am J Med 65: $342,1978$.

15) Heck LW, Alarcon GS, Ball GC, et al. Pure red cell aplasia and proteinlosing enteropathy in a patient with systemic lupus erythematosus. Arthritis Rheum 28: 1059, 1985.

16) Frazen $P$, Friman $C$, Pettersson $T$, Fyhequist F, Ruutu T. Combined pure red cell aplasia and primary autoimmune hypothyroidism in systemic lupus erythematosus. Arthritis Rheum 30: 839, 1987.

17) Ilan $Y$, Naparstek $Y$. Pure red cell aplasia associated with systemic lupus erythematosus: remission after a single course of intravenous immunoglobulin. Acta Hematol 89: 152, 1993.

18) Yamasaki K, Niho Y, Yanase T. Erythroid colony forming cells in systemic lupus erythematosus. J Rheumatol 11: 167, 1984.

19) Otsuka T, Okamura S, Harada M, et al. Multipotent hemopoietic progenitor cells in patients with systemic lupus erythematosus. J Rheumatol 15: 1085,1988

20) Budman DR, Steinberg AD. Hematologic aspects of systemic lupus erythematosus. Ann Intern Med 86: 220, 1977.

21) Fitchen JJ, Cline MJ, Saxon A, Golde DW. Serum inhibitors of hematopoiesis in a patient with aplastic anemia and systemic lupus erythematosus: recovery after exchange plasmapheresis. Am J Med 66: $537,1979$.

22) Dainiaak N, Hardin J, Floyd V, Callahan M, Hoffman R. Humoral suppression of erythropoiesis in systemic lupus erythematosus (SLE) and rheumatoid arthritis. Am J Med 69: 537, 1980.

23) Wisniewski D, Strife A, Wachter M, Clarkson B. Regulation of human peripheral blood erythroid burst-forming unit growth by $\mathrm{T}$ lymphocytes and $\mathrm{T}$ lymphocyte sub-populations defined by OKT4 and OKT8 monoclonal antibodies. Blood 65: 456, 1985.

24) Nielsen B, Jessen P, Hokland P. Regulation of autologous T-lymphocyte clones on in vitro growth of BFU-E: enhancing effects of both CD4 and CD8-positive clones. Eur J Haematol 46: 26, 1991.

25) Mangan KF, Hartnett ME, Matis SA, Winkelstein A, Abo T. Natural killer cells suppress human erythroid stem cell proliferation in vitro. Blood 63: 260, 1984.

26) Nossent H, Swaak TJG, Berden JHM. Systemic lupus erythematosus: Analysis of disease activity in 55 patients with end-stage renal failure treated with hemodialysis or continuous ambulatory peritoneal dialysis. Am J Med 89: 169, 1990.

27) Caplon N, Diskin C, Peterson J. The long-term clinical course of systemic lupus erythematosus in end-stage renal disease. N Engl J Med 308: 186, 1983.

28) Kimberly RP, Lockshin MD, Sherman RL, Beary JF, Mouradian J, Cheigh JS. 'End-stage' lupus nephritis: Clinical course to and outcome on dialysis. Medicine 60: 277, 1981.

29) Fialkow RZ, Rubin J. Active lupus in a patient receiving long-term hemodialysis. South Med J 79: 516, 1986.

30) Frickhofen N, Abkowitz JL, Safford M, et al. Persistent B19 parvovirus infection in patients infected with human immunodeficiency virus type 1: a treatable cause of anemia in AIDS. Ann Intern Med 113: 926, 1990.

31) Marmont AM. Therapy of pure red cell aplasia. Semin Hematol 28: 285, 1991.

32) Aoki I, Higashi K, Homori M, Chikazawa H, Ishikawa K. Responsiveness of bone marrow erythropoietic stem cells (CFU-E and BFU-E) to recombinant human erythropoietin (rh-Ep) in vitro in aplastic anemia and myelodysplastic syndrome. Am J Hematol 35: 6, 1990.

33) Hotta T, Maeda H, Suzuki I, Chung TG, Saito A. Selective inhibition of erythropoiesis by sera from patients with chronic renal failure. Proc Soc Exp Biol Med 186: 47, 1987.

34) Kushner D, Beckman B, Nguyen L, et al. Polyamines in the anemia of end-stage renal disease. Kidney Int 39: 725, 1991.

35) Sungur C, Sungur A, Arik N, et al. Bone marrow involvement in systemic amyloidosis: Another mechanism for erythropoietin resistance. Nephron 63: 232, 1993.

36) Otsuka T, Nagasawa K, Harada M, Niho Y. Bone marrow microenvironment of patients with systemic lupus erythematosus. J Rheumatol 29: 967, 1993. 